\title{
Atmosphere response to pre-earthquake processes revealed by satellite and ground observations. Case study for few strong earthquakes in Xinjiang, China (2008-2014)
}

\author{
Dimitar Ouzounov ${ }^{*}, 1$, Sergey Pulinets ${ }^{2}$, Ke Sun ${ }^{3}$, Xuhui Shen ${ }^{4}$, Menas Kafatos ${ }^{1}$ \\ (1) Center of Excellence in Earth Systems Modeling \& Observations (CEESMO) Chapman University, One University \\ Drive, Orange, CA 92866, USA \\ (2) Space Research Institute, Russian Academy of Sciences, 84/32 Profsoyuznaya Str, Moscow, 117997, Russia \\ (3) Institute of Earthquake Prediction, China Earthquake Administration, 63 Fuxing Road, Haidian District, Beijing, \\ 100036, China \\ (4) Institute of Crustal Dynamics, China Earthquake Administration, Anningzhuang Rd.1, Xisanqi, Haidian District, \\ Beijing, 100085, China
}

Article history: received January 14, 2019; accepted January 31, 2020

\begin{abstract}
We are presenting the latest results of multi-sensor observations of short-term pre-earthquake phenomena preceding significant earthquakes. We study satellite thermal infrared radiation (OLR) anomalous signals in association with three major earthquakes, which occurred in Xinjiang province, China at different periods M7.3 of 02.12.2014; M6.2 of 08.12.2012; and M7.2 of 03.20.2008. We systematically apply multi-sensor satellite thermal data and ground temperature /humidity and estimates of the atmospheric chemical potential (ACP) parameter. Data analyses include NOAA NPOESS, the Chinese geostationary satellite FY-2D, and in-situ hourly NOAA data from the Hotan weather station. In all three cases, we detected atmospheric satellite OLR anomalies developed near the epicenter area and ACP increases (significant change for 2008 and 2014, weak for 2012) over the major Altyn Tagh fault lines within 10-20 days before the earthquake event. These findings demonstrate the occurrence and reoccurrence of transient variations of these parameters, implying their connection with the earthquake preparation process.
\end{abstract}

Keywords: Precursors; Thermal anomaly; LAIC; Radon.

\section{Introduction}

The observational evidence from the last twenty years provided an extensive scientific collection of anomalous transient patterns preceding earthquakes. Some of them have shown [Tronin et al., 2002; Liu et al., 2004, 2010; Pulinets and Boyarchuk, 2004, Pulinets and Davidenko, 2013; Tramutoli et al., 2005, 2013; Hattori 


\section{Dimitar Ouzounov et al.}

et al., 2006] that studying atmospheric variability could also reveal active tectonic processes in the Earth's crust. Despite the multiple singular reports for enhancement in the transient atmospheric fields around the time of significant earthquake events [Ouzounov et al., 2007; Nemec et al., 2009; Pergola et al., 2010; Lisi et al., 2010], there is still of lack of coordinated observations. Therefore it is very much needed to understand the atmospheric and environmental processes associated with active tectonic faulting and significant earthquakes. Two extended summaries of the multi-parameter approach for studying pre-earthquake processes were published recently [Ouzounov et al., 2018; Pulinets and Ouzounov, 2018]. These two volumes show the variety of parameters seismic, atmospheric, electromagnetic, and geochemical and the historical perspective of this research and are opening this topic to a broader geoscience community.

The latest major earthquake in Xinjiang province, China, had a magnitude of 7.2 and occurred in the Southern part of the province on 12 February 2014 (Figure 1) followed by several aftershocks (see Table 1).

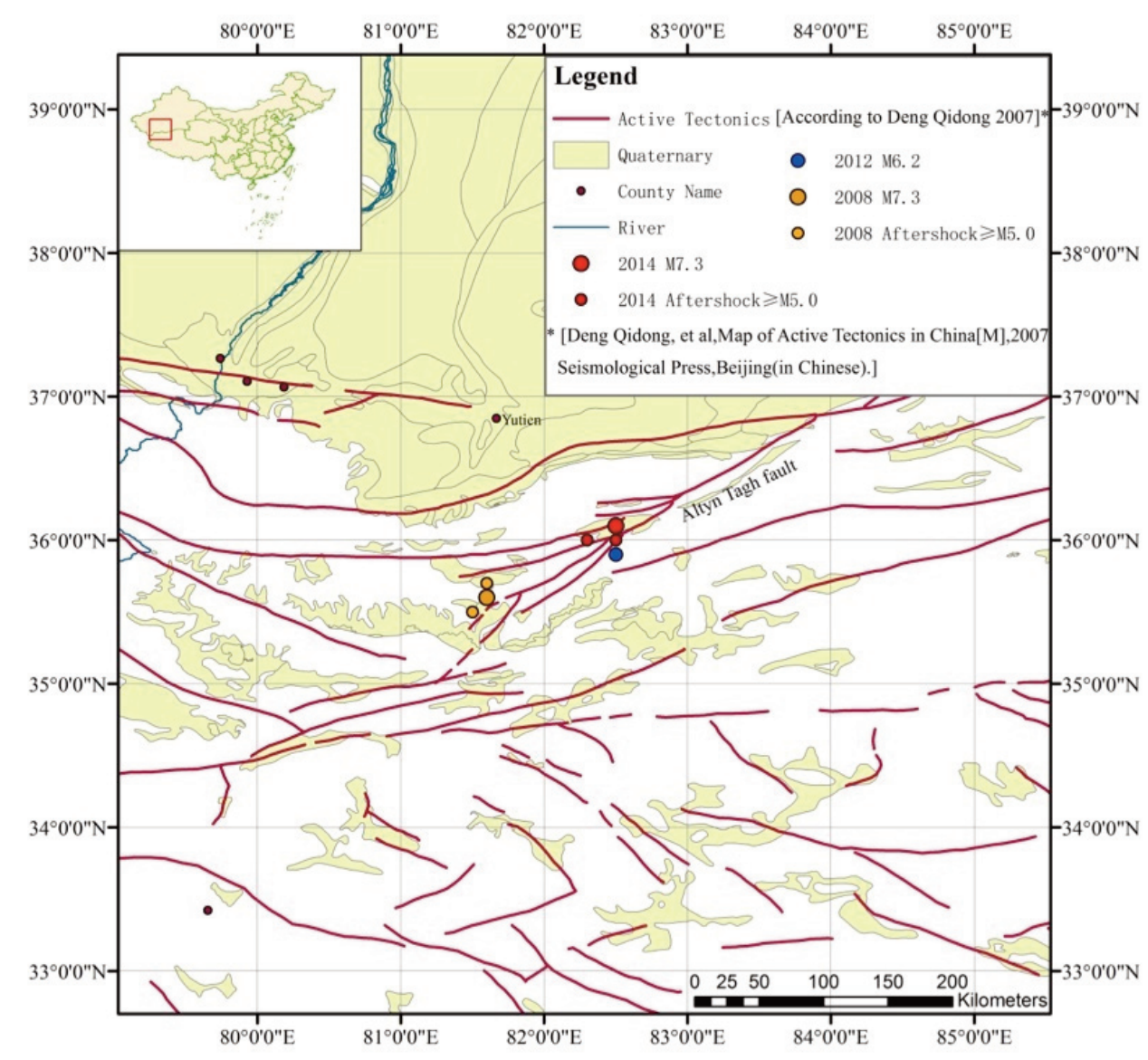

Figure 1. Seismotectonic map of Xinjiang, China (Deng et al, 2007) and epicenter location of main earthquakes and major aftershocks: M7.2 of 02.12.2014 with red, M6.2 of 08.12.2012 with blue, M7.2 of 03.20.2008 with orange. Major tectonic lineaments are in red.

A similar type of earthquake occurred in the same region in 2008 and 2012. This study explores the relationship between atmospheric processes and the occurrence of the significant earthquakes in Xinjiang province - M7.2 of 02.12.2014; M6.2 of 08.12.2012; M7.2 of 03.20.2008 by analyzing data from ground and satellite observations. For the first time, we test the reappearance of this relationship for major earthquakes occurred in the same seismotectonic region by using multi-sensor physical observations.

We have analyzed two different physical parameters characterizing the atmosphere's state during the time of earthquakes in Xinjiang province: 1. Earth outgoing radiation measured at the top of the atmosphere from different 
satellite platforms (polar and geosynchronous); and 2. Atmospheric temperature, relative humidity, and computed atmospheric chemical potential from ground observations. This approach provides a complex view of the scale and physics of changes in the atmospheric processes related to tectonic activity.

Our first reports on the pre-earthquake detection of satellite-based anomalies associated with major seismicity in Xinjiang province was in response to the M7.3 earthquake in 2014 [Sun et al., 2014; Ouzounov et al., 2015]. Meanwhile, OLR data associated with five earthquakes $(M>6.0)$ in the Xinjiang area of China between 2008 and 2014 were analyzed [Jing et al., 2016]. The spatial-temporal analysis results confirmed that three major events (the same event we analyze in this paper) had been identified with significant thermal anomalies.

\begin{tabular}{|c|c|c|c|c|c|c|}
\hline Date & Time & $\operatorname{Lan}\left({ }^{\circ}\right)$ & Lon $\left({ }^{\circ}\right)$ & Depth & Magnitude & Location \\
\hline $3 / 26 / 08$ & 6:39:28 PM & 35.70 & 81.60 & 33.00 & M5.0 & XinJiang Yutian \\
\hline $3 / 21 / 08$ & $8: 26: 17$ AM & 35.50 & 81.50 & 33.00 & M5.2 & XinJiang Yutian \\
\hline $3 / 21 / 08$ & 8:10:41 AM & 35.50 & 81.50 & 33.00 & M5.0 & XinJiang Yutian \\
\hline $3 / 21 / 08$ & 7:12:03 AM & 35.50 & 81.50 & 33.00 & M5.2 & XinJiang Yutian \\
\hline $3 / 21 / 08$ & $6: 38: 59 \mathrm{AM}$ & 35.50 & 81.50 & 33.00 & M5.1 & XinJiang Yutian \\
\hline $3 / 21 / 08$ & 6:33:03 AM & 35.60 & 81.60 & 33.00 & M7.3 & XinJiang Yutian \\
\hline $8 / 12 / 12$ & 6:47:12 PM & 35.90 & 82.50 & 30.00 & M6.2 & XinJiang Yutian \\
\hline $3 / 22 / 14$ & $8: 58: 19 \mathrm{PM}$ & 36.00 & 82.30 & 8.00 & M5.0 & XinJiang Yutian \\
\hline $3 / 13 / 14$ & 1:55:43 AM & 35.90 & 82.30 & 8.00 & M4.5 & XinJiang Yutian \\
\hline $2 / 15 / 14$ & 8:32:59 PM & 36.00 & 82.30 & 7.60 & M4.6 & XinJiang Yutian \\
\hline $2 / 13 / 14$ & 8:08:41 AM & 36.00 & 82.50 & 6.20 & M4.7 & XinJiang Yutian \\
\hline $2 / 13 / 14$ & 8:07:03 AM & 36.00 & 82.50 & 7.20 & M4.5 & XinJiang Yutian \\
\hline $2 / 13 / 14$ & 3:09:23 AM & 36.00 & 82.40 & 6.10 & M4.9 & XinJiang Yutian \\
\hline $2 / 13 / 14$ & 2:00:06 AM & 35.90 & 82.40 & 7.10 & M4.5 & XinJiang Yutian \\
\hline $2 / 12 / 14$ & 7:14:21 PM & 36.20 & 82.50 & 8.20 & M4.6 & XinJiang Yutian \\
\hline $2 / 12 / 14$ & 6:00:08 PM & 36.00 & 82.50 & 5.80 & M4.9 & XinJiang Yutian \\
\hline $2 / 12 / 14$ & 5:24:43 PM & 36.00 & 82.50 & 4.70 & M5.7 & XinJiang Yutian \\
\hline $2 / 12 / 14$ & 5:19:50 PM & 36.10 & 82.50 & 12.00 & M7.3 & XinJiang Yutian \\
\hline $2 / 11 / 14$ & 10:14:57 AM & 36.10 & 82.40 & 11.00 & M5.4 & XinJiang Yutian \\
\hline
\end{tabular}

Table 1. Earthquake catalog of main events M7.2 of 02.12.2014, M6.2 of 08.12.2012, M7.2 of 03.20.20808 (highlighted) and aftershocks. Data source - China earthquake Administration (CEA).

\section{Methods and Data Analysis}

\subsection{Satellite observations}

One of the main parameters we characterize the Earth's radiation environment is the outgoing long-wave-earth radiation (OLR, eight to12 $\mu \mathrm{m}$ ). OLR occur at the top of the atmosphere integrating and are integrated emissions from the ground, the lower atmosphere, and clouds [Ohring and Gruber, 1982] and primarily been used to study Earth's radiative budget and climate [Gruber and Krueger, 1984; Mehta and Susskind, 1999]. The National Oceanic and Atmospheric Administration (NOAA) Climate Prediction Center provides daily and monthly OLR databases on POES polar orbit observations.

The algorithm for analyzing the Advanced Very High-Resolution Radiometer (AVHRR) OLR data is not directly measured, but rather is calculated from the raw data using a different algorithm [Gruber and Krueger, 1984]. The NOAA estimate of total longwave radiation flux is obtained by applying a regression equation (infra-red) IR window observations. 


\section{Dimitar Ouzounov et al.}

$$
T_{f}=T_{w}\left(a+b T_{w}\right)
$$

$T_{w}$ - is the radiance equivalent of brightest temperature BT (K) in the IR window over nadir, $T_{f}$ is the flux equivalent $\mathrm{BT}(\mathrm{K})$, $\mathrm{a}$ and $\mathrm{b}$ are the regression coefficients.

OLR is mainly sensitive to near-surface and cloud temperatures. A daily mean data footprint covering a significant area $\left(90^{\circ} \mathrm{N}-90^{\circ} \mathrm{S}, 180^{\circ} \mathrm{W}-180^{\circ} \mathrm{E}\right)$ and with a spatial resolution of $2.5^{\circ}$ was used to study the OLR variability in the zone of earthquake activity [Ouzounov et al., 2007,2018; Xiong at al., 2010]. An increase in radiation and a transient change in OLR were recorded at the top of the atmosphere over seismically active regions. This phenomenon was proposed to be related to thermodynamic processes in the earth's surface. In the first approximation, we can define the atmospheric anomaly in the Euler frame of reference by subtracting the mean value. The mean can be defined as the average for the same day of the year, local time, and location over more than ten years. The advantage of this approach is its simplicity and effectiveness with the availability of long-time satellite observations. Following this, the OLR anomalous variations were defined [Ouzounov et al., 2007] as an E_index. This index is similar to the definition of an anomalous thermal field proposed by Tramutoli et al. 2005. The E_index was constructed as statically estimated variability in OLR values for specific locations and periods:

$$
E_{-} \text {Index }_{i, j}(t)=\left(S^{*}\left(x_{i, j}, y_{i, j}, t\right)-\overline{S^{*}}\left(x_{i, j}, y_{i, j}, t\right)\right) / \sigma_{i, j}
$$

Where: $t=1$, K days, $S^{*}\left(x_{i, j}, y_{i, j}, t\right)$ is the current OLR and $\overline{S^{*}}\left(x_{i, j}, y_{i, j}, t\right)$ is the computed mean of the OLR field, defined for multiple years of observations over the same location and same local time, $t_{i, j}$ is the standard deviation. We use the Anomaly Index, a modified version of $E_{-} I n \operatorname{dex}$ (Eq 2), which represents the regional calibration of $E_{-}$Index estimates we apply for Xinjiang province and define as:

$$
\text { Anomaly Index }=\left(\mathrm{A}^{*} \mathrm{E}_{-} \text {Index }\right) / \mathrm{B}
$$

Where A and B are regional calibration coefficients, A - is a mask, mainly defined by the regional seismotectonic patterns and frequency of appearance of OLR anomalies for the historical events. The Xinjiang province values vary around 0.6-0.8; B - normalizes each of NOAA 15 and 18-time series of OLR data to the same time coverage (ten years). Range of $B$ for the Xinjiang province region 1-3.5. The Anomaly Index data have been processed with a resolution of $\left(2.5^{\circ} \times 2.5^{\circ}\right)$, and the output maps have been processed with additional preprocessing to avoid aliasing of short wavelengths and with spatial filtering based on a "minimum curvature" algorithm [Ouzounov et al., 2018].

In addition to NOAA OLR daily data, we analyzed and OLR from the FY-2D Chinese geostationary satellite. FY-2D is very similar to GMS and GOES-3/7, and the primary payload is a Visible and Infrared Spin Scan Radiometer (VISSR), which obtains hourly full-disk images of the Earth, in five channels: VIS (0.55-0.90 $\mu \mathrm{m})$, IR (10.3-11.3;11.512.5;3.5- $4.0 \mu \mathrm{m})$ and WV (6.3-7.6 $\mu \mathrm{m})$. Two thermal infrared channels and water vapor channels were used to calculate OLR from $50 \mathrm{~N}$ to $50 \mathrm{~S}, 55 \mathrm{E}$ to $155 \mathrm{E}$, its resolution is 0.1 degree. The method for calculating OLR of FY2C and FY- 2D geostationary satellite data is similar to NOAA OLR. Based on the specific inverse model using the measurements in the FY-2D, the window, and water vapor channels, the quality of FY-2D OLR products nearly similar by comparing with NOAA OLR products. The difference between the two products ranges from 0 to $20 \mathrm{~W} / \mathrm{m}$, with the maximum difference being $20 \mathrm{~W} / \mathrm{m}$. [Wu, 2008].

Our analyses include NOAA OLR data between 2004 and 2014 and FY-2D for 2007- 2014. The OLR survey about M7.2 of 02.12.214 containing the pixels nearest to the epicentral area for July 2013-June 2014 (Figure 2a) show that the initial indication of the formation of a transient atmospheric anomaly was detected on January 21 (22 days before the mainshock), and the maximum was co-located with epicenter (Figure 3). The OLR reference field was computed for January 1 to April 30 using all available NOAA data (2005-2014), and the level of Anomaly index > 2 is significant. During the October 2013-January 2014, two others transient OLR field anomalies were observed near the epicentral area before reaching the maximum on January 21 . The temporal variability (Figure 3) map for January 20 - February 12, 2014, confirmed that the maximum change in the OLR state over the epicentral area did occur on January 21. The enhancement of radiative emission could be explained by the anomalous flux of the latent heat over the area of increased tectonic activity observed within a few days before the earthquake [Pulinets and Ouzounov, 2011; Ouzounov et al., 2007, 2011; Cervone et al., 2006]. The 2012 (M 6.2) and 2008 (M7.2) event shows similar OLR anomalies (Figure 2, b and c), and particularly the 2012 event has been identified with the smallest energy. 
All anomalies were building near the epicenter area, over the major Altyn Tagh fault lines within 10-15 days before the seismic event. Thus, it probably is connected with the gas release enhancement and additional flux emission and provides information about major fault activation in this area.
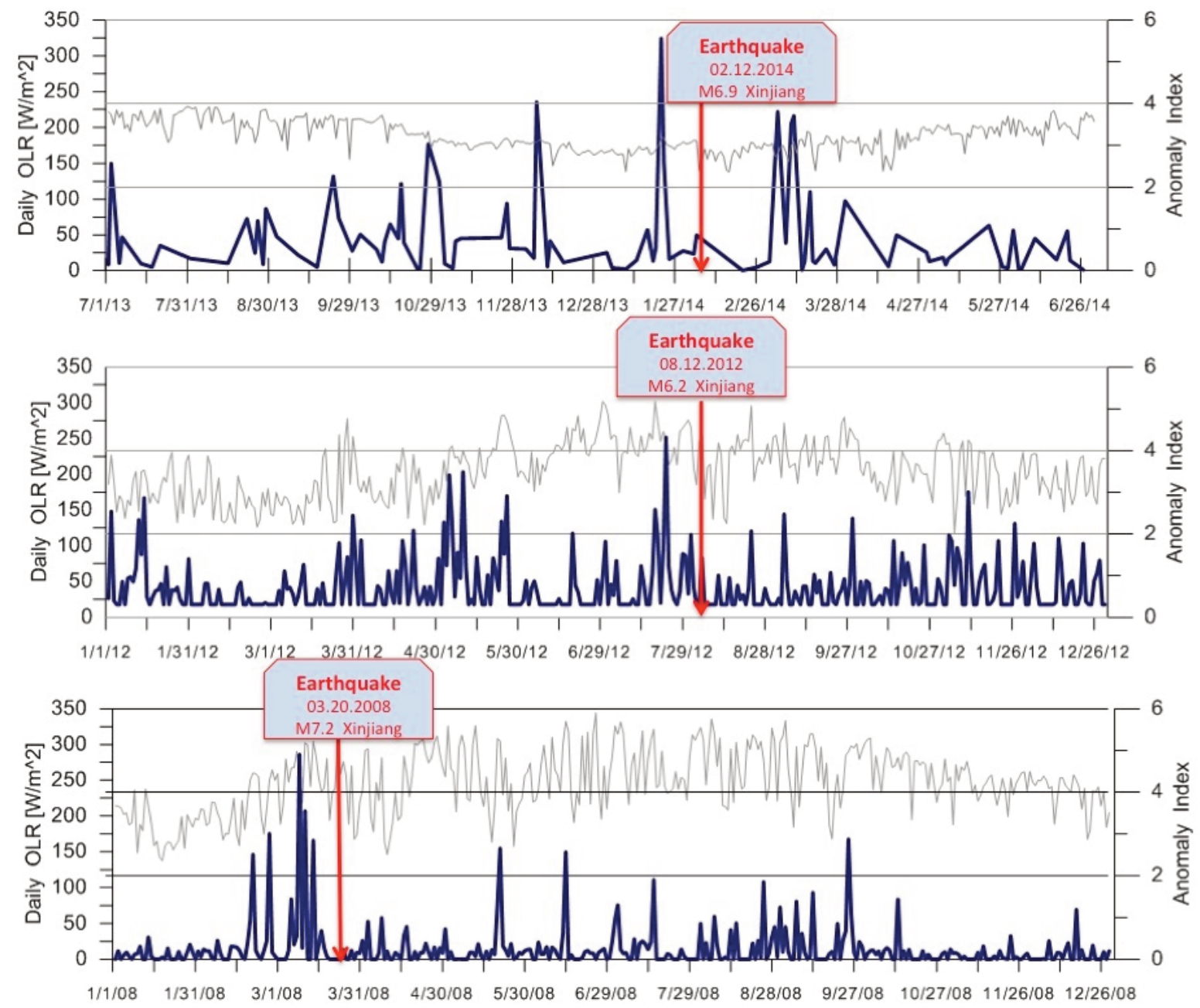

Figure 2. One year of continues time series of daily raw OLR (thin curve) and computed OLR anomalous index (bolded curve) observed from NOAA AVHRR for periods of: A/(top) 07.01.2013-06.30.2014 for M7.2 of 02.12.2014; B/(middle) 01.01.2012-12.31.2012 310 for M6.2 of 08.12.2012; and C/(bottom) 01.01.2008 -12.01.2008 for M7.2 of 03.20.2008 Xinjiang province, China.

A join plot of OLR NOAA and FY-2D over the epicentral areas for January 2 until February 15 is presented in Figure 4. Anomaly index for polar OLR (NOAA) occurred on January 21, and for geosynchronous OLR (FY-2D), anomalies indicated started on January $24,21.30 \mathrm{~h}$, and the temporal persistence in the build of the anomaly was detected on January 31 (Figure 5 NOAA and FY-2D zones are indicated with grey). For both data types, the abnormality level starts with Anomaly index $>2$, and the anomaly definition was considered for Anomaly index $>$ 4 (Figure 5). FY-2D OLR data showing the trend in detecting OLR signals as NOAA by revealing anomalous value with the persistence of more than 6 hours on January 31, 2014 (15.30h-21.30h) shown in Figures $4 \mathrm{f}, \mathrm{g}$, h. Both transient anomalies were revealed in comparison with reference line $t-10$ years reference for NOAA data and seven years for FY- 2D data respectively [Ouzounov et al., 2007]. The differencing days of appearance (Figure 5) probably result from differences in the spatial/temporal resolution, local time of observations, and the different types of sensor payload on both NOAA15/18 and FY-2D platforms. More investigation is needed to perform a cross-platform correlation between the two OLR products. 


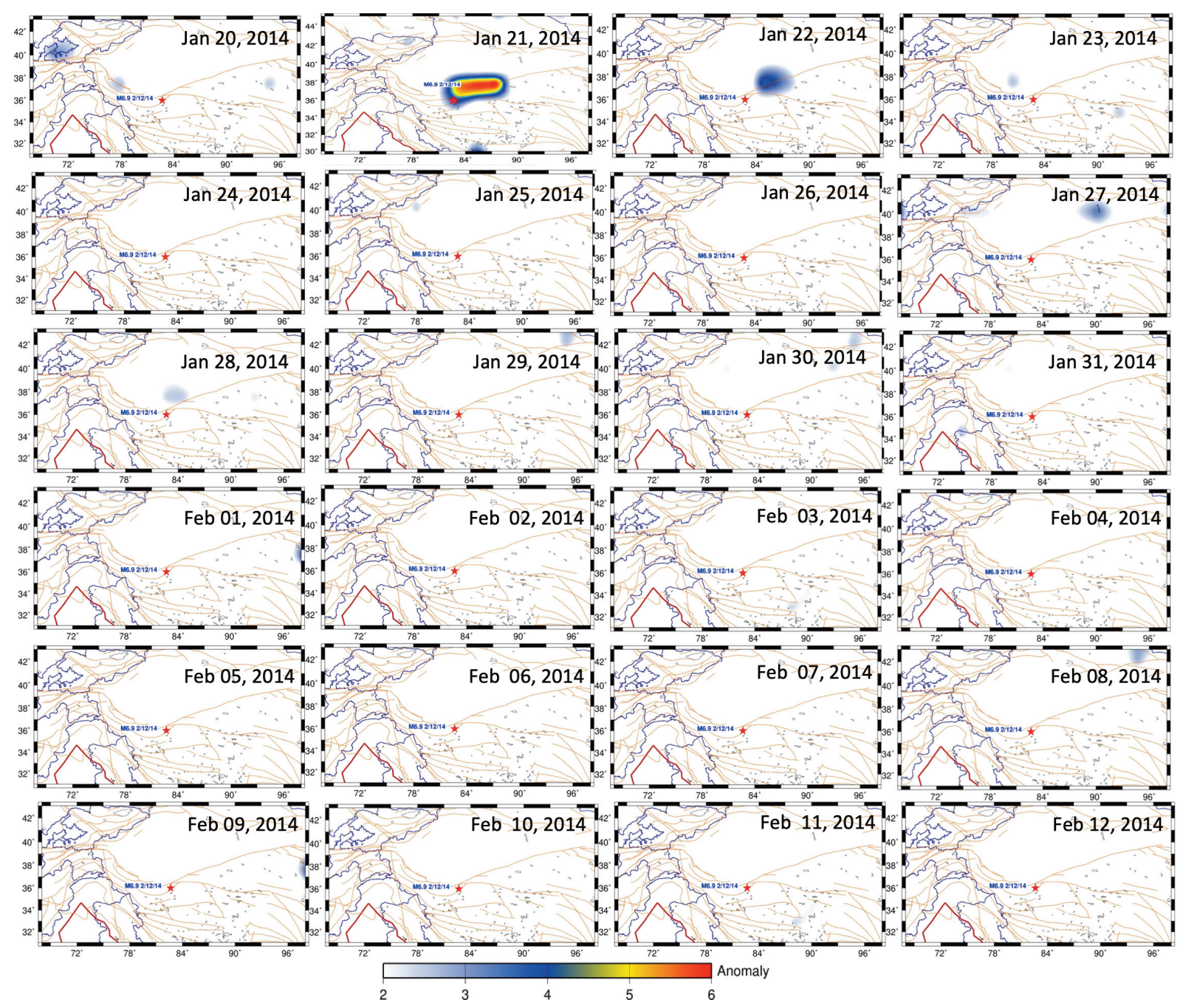

Figure 3. Mosaic of OLR daily anomaly index maps based on NOAA AVHRR data for period of 01.20.2014-02.12.2014 over Xinjiang province, China. With star is M7.2 of 02.12.2014 earthquake. Major faults are with brown color; major platform boundaries are with red color. 


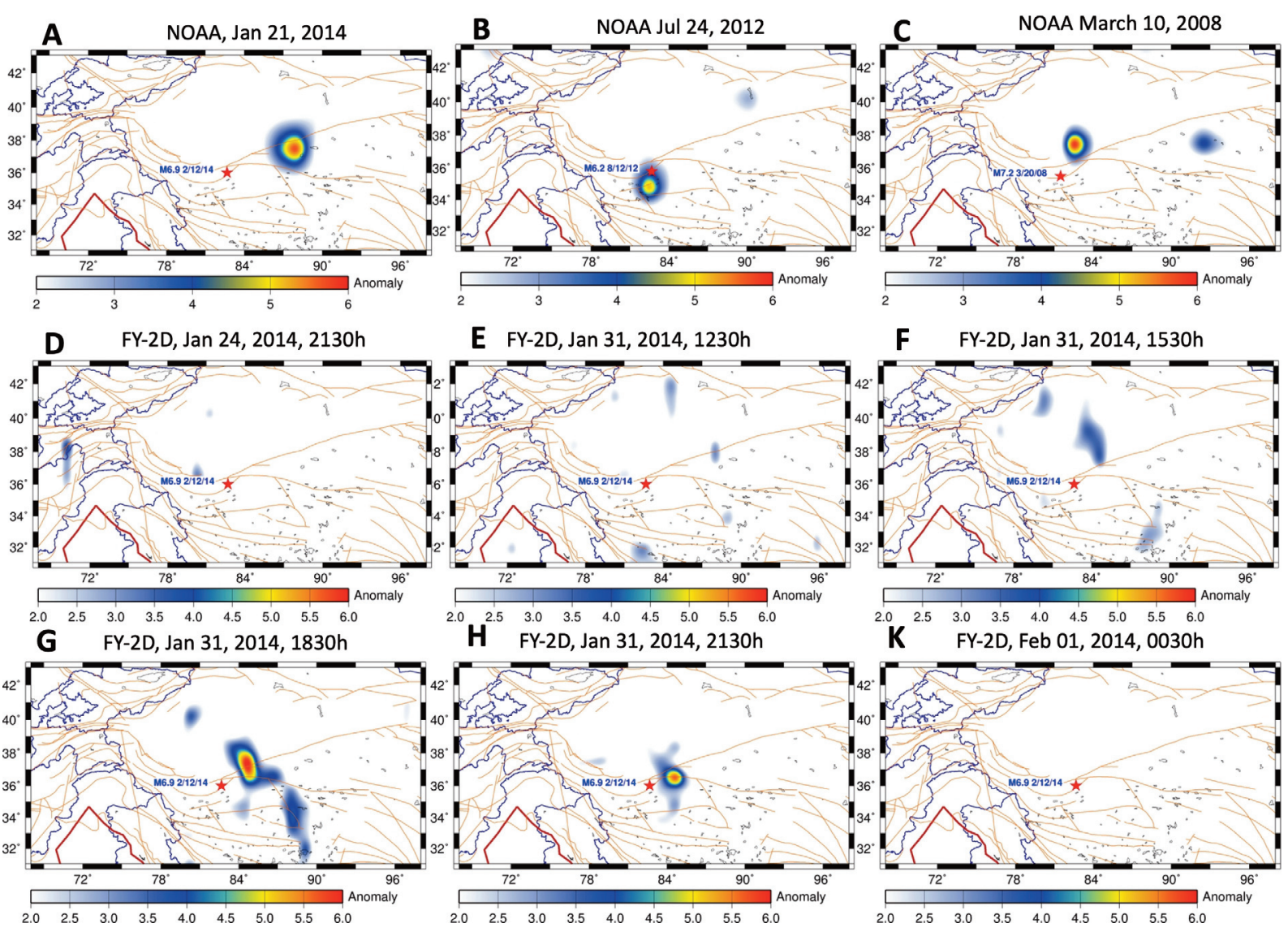

Figure 4. Daily OLR anomalous maps revealing static (NOAA) and dynamic (FY-2D) pre-earthquake signatures: A-C for NOAA OLR (M7.2 of 02.12.2014, M6.2 of 08.12.2012, M7.2 of 03.20.2008) and D-K for FY-2D (M7.2 of 02.12.2014): A/ The NOAA anomaly of Jan 21, 2014, 21 days in advance to M7.2 of 02.12.2014; B/ NOAA anomaly of 07.24.2012, 19 days in advance to M6.2 of 08.12.2012; C/ The NOAA anomaly of 03.10.2008, 10 days in advance to M7.3 03.20.2008; D/ FY-2D, Jan 24, 2014, 2130h - a weak anomaly; E/ FY-2D, Jan 31, 2014, 1230h - no anomaly / FY2D, Jan 31, 2014, 1530h - anomaly starts (begin of the anomalous build-up); G/ FY-2D, Jan 31, 2014, 1830h anomaly; H/ FY-2D, Jan 31, 2014, 2130h- strong anomaly; and K/ FY-2D, Feb 01, 2014, 0030h - no anomaly (the anomalous patterns end). 


\section{Dimitar Ouzounov et al.}

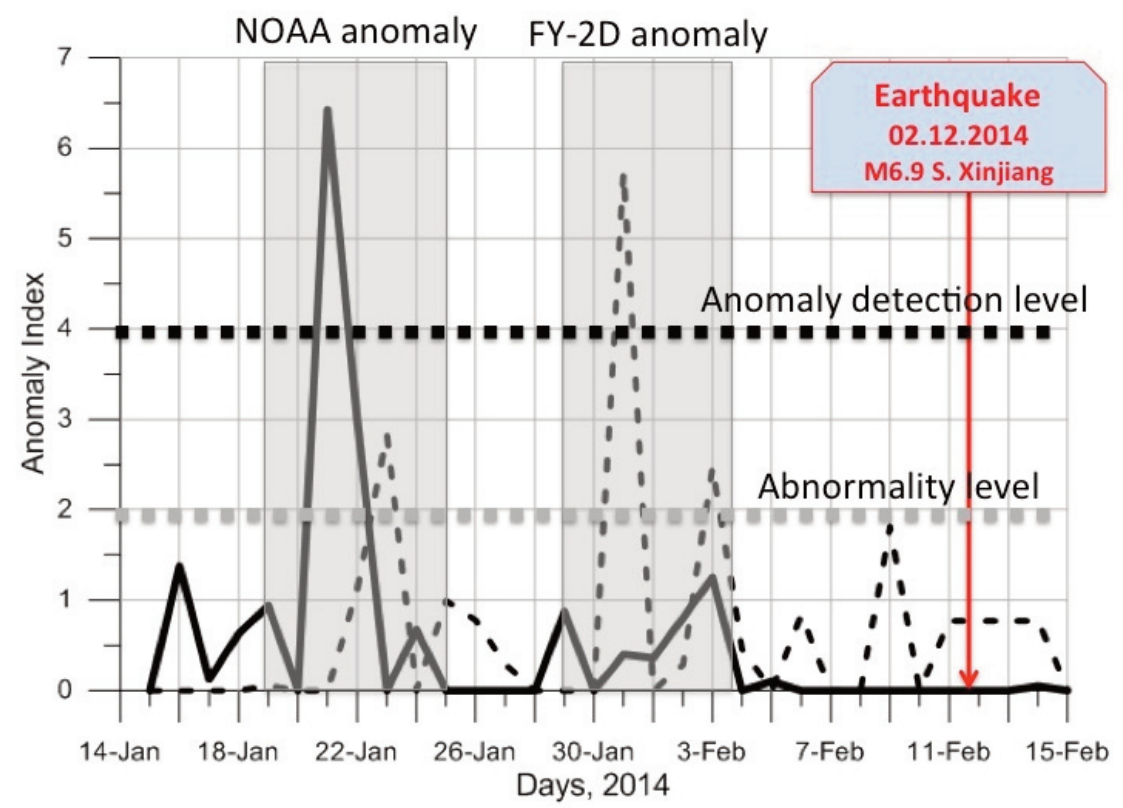

Figure 5. Time series of anomaly Index of NOAA OLR (solid line) and FY-2D OLR (dash line) build for 45 days (Jan 2-Feb $15,2014)$ over the epicentral area $\left(36^{\circ} \mathrm{N} 82^{\circ} \mathrm{E}\right)$ of $\mathrm{M} 7.2$ of 02.12 .2014 earthquake. With the dash grey line, the definition of abnormality level $(>2)$. With a bold black line, the description of anomaly detection level $(>4)$.

\subsection{Ground atmospheric measurements}

To understand the day-by-day variability of the daytime and nighttime temperature during the time earthquake events, we analyzed the hourly temperature and relative humidity near the epicenter. We used in-situ hourly global surface air temperature for Hotan weather station provided by NOAA NCDC. (Location $37^{\circ} \mathrm{N} 80^{\circ} \mathrm{E}$, about $270 \mathrm{~km}$ north from the epicentral area). The presence of ions in the atmosphere creates a possibility for water vapor molecules to join these ions through the hydration process, which is different from condensation. In the process of condensation, the chemical potential is equal to the Latent heat, which is $\mathrm{Q}=40.683 \mathrm{~kJ} / \mathrm{mol}$ or U0 $=0.422$ e V per one molecule. The evaporation/condensation process, which is the phase transition of the first order, always takes place during the chemical potential equality. However, newly formed ions have different chemical potential; what we should consider in the one-component approximation we introduce the correction to the chemical potential DU which considers this circumstance.

In this case, the real chemical potential can be expressed as:

$$
\mathrm{U}(\mathrm{t})=\mathrm{U} 0+\Delta \mathrm{U} \cdot \cos 2 \mathrm{t}
$$

Where $\mathrm{U} 0$ is the chemical potential for pure water, and $\mathrm{U}(\mathrm{t})$ is the chemical potential where the ionization and hydration are considered. By $\cos 2 t$ we consider the daily changes of solar radiation. The increase of the water molecules chemical potential $\Delta \mathrm{U}$ (which can be derived from (4)) indicates the strength of the nucleation process and can be used as an indicator of earthquake approaching according to Boyarchuk et al., [2010].

We analyzed hourly surface air temperature data obtained from Hotan ground station for two months around each of the events (30 days before and 15 days after) to observe the normal and abnormal state of the air temperature (T) and relative humidity (RH). The time series of T, RH, and ACP for February 1 - March 31, 2014 (M7.2 03.20.2008), July 1 - August 30, 2012 (M6.2 08.12.2012), and January 1 - February 28, 2014 (M7.2 02.12.2014) are shown respectively in Figure 6a, 6b and 6c. We computed the hourly ACP (Eq 4, 5) in order to the follow the nucleation processes during the earthquake preparation phase. The transient rapid increase of ACP could be seen in the onset of all Earthquake cases. The maximum amplitude of ACP (0.06) was reached for the M7.2 of 2008 along with the most 
significant time lag, probably because the size of nucleation is proportional to the magnitude (the 2008 earthquake had the largest $\mathrm{M}$ of 7.2). On the same time scale, RH drops, while T is rising. Two of the time intervals shown in Figure 6 are overlapped for the same month of February for 2008 (Figure 6a) and 2014 (Figure 6c) accordingly. During Feb 1-16 (2008, Figure 6a), T, RH, and ACP show normal day-to-day variability. However, the same period of February 1 - 16 for 2014 (Figure 6c) shows definite transient change as ACP increases, and RH drops, probably because this period coincides with the earthquake preparation phase for M6.5 of 02.12.2014. The Time series of T, H, and ACP on Figure 6 reparents the natural atmospheric variability during the thermodynamic changes. Plots are presenting "raw" in-situ data without statistical validation. We choose this approach only to illustrate the first order of processes in the atmosphere's different states. Of course, statistical analysis is needed to show the significance of those processes and separate the real anomalies from the false alarms.

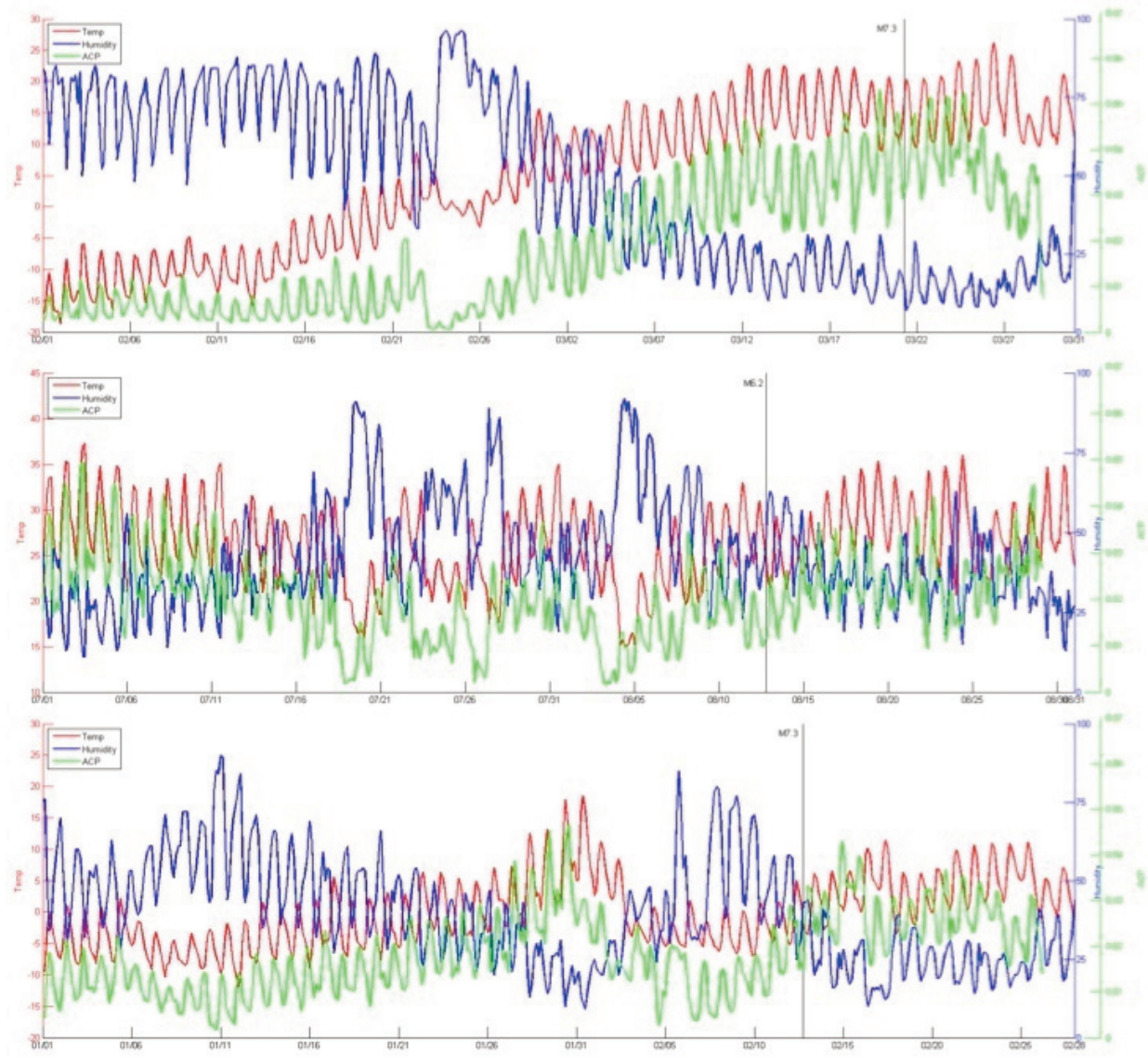

M7.2, 2008-03-20

M6.2, 2012-08-12

M6.9, 2014-02-12

Figure 6. Time series of hourly counts of temperature (red), relative humidity (blue) and atmospheric chemical potential (green) obtained from Hotan ground stations $\left(37^{\circ} \mathrm{N} 80^{\circ} \mathrm{E}\right)$ within two months around the time of M7.2 of 02.12.2014, M6.2 of 08.12.2012, and M7.2 of 03.20.2014.

\section{Discussion and conclusions}

Our preliminary analysis of atmospheric parameters from satellite and ground observations during the three major earthquakes in Xinjiang province China (M7.2 of 02.12.2014; M6.2 of 08.12.2012; M7.2 of 03.20.2008) demonstrated the presence and re-occurrences of related variations of these parameters, implying their connection with the earthquake preparation process (see Table 2). 


\section{Dimitar Ouzounov et al.}

\begin{tabular}{|c|c|c|c|c|c|c|}
\hline & \multirow[b]{2}{*}{ Earthquakes } & \multicolumn{5}{|c|}{ Anomalies and trends } \\
\hline & & $\begin{array}{l}\text { NOAA OLR } \\
\text { (anomaly) }\end{array}$ & $\begin{array}{l}\text { FY-2D OLR } \\
\text { (anomaly) }\end{array}$ & $\begin{array}{l}\text { Air Temperature } \\
\text { (trend) }\end{array}$ & $\begin{array}{l}\text { Relative } \\
\text { Humidity } \\
\text { (trend) }\end{array}$ & $\begin{array}{l}\text { Atmospheric Ch. } \\
\text { Potential (trend) }\end{array}$ \\
\hline 1 & $\begin{array}{l}\text { M7.2 of } 02.12 .14 \\
\text { Southern Xinjiang, } \\
\text { China }\end{array}$ & $\begin{array}{l}\text { Jan } 21,2014 \\
\text { strong } \\
\text { (-22 days) }\end{array}$ & $\begin{array}{c}\text { Jan } 23 \text { (weak), } \\
\text { Jan } 31 \text { (strong) } \\
\text { (-12 days) }\end{array}$ & $\begin{array}{l}\text { Moderate } \\
\text { increase }\end{array}$ & $\begin{array}{l}\text { Decrease } \\
01.31 .14\end{array}$ & $\begin{array}{l}\text { Increase starts } \\
\text { on } 01.30 .14\end{array}$ \\
\hline 2 & $\begin{array}{l}\text { M6.2 of 08.12.2012, } \\
\text { Xinjiang - Xizang } \\
\text { border Region, China }\end{array}$ & $\begin{array}{l}\text { July } 24,2012 \\
\text { strong } \\
\text { (-19 days) }\end{array}$ & Not processed & $\begin{array}{l}\text { Moderate } \\
\text { increase }\end{array}$ & $\begin{array}{c}\text { Moderate } \\
\text { decrease starts } \\
\text { on } 08.02 .12\end{array}$ & $\begin{array}{c}\text { Moderate } \\
\text { increase starts } \\
\text { on } 08.03 .12\end{array}$ \\
\hline 3 & $\begin{array}{c}\text { M7.2 of 03.20.08, } \\
\text { Xinjiang - Xizang } \\
\text { border Region, China }\end{array}$ & $\begin{array}{l}\text { March } 10,2008 \\
\text { strong } \\
(-10 \text { days })\end{array}$ & Not processed & $\begin{array}{l}\text { Clear increase } \\
\text { starts on } \\
02.27 .08\end{array}$ & $\begin{array}{l}\text { Clear decrease } \\
\text { starts on } \\
02.25 .08\end{array}$ & $\begin{array}{l}\text { Clear increase } \\
\text { starts on } \\
02.26 .08\end{array}$ \\
\hline
\end{tabular}

Table 2. Summary of the observed satellite and ground measured atmospheric parameters and their anomalous characteristics prior to the M7.2 of 02.2012.14; M6.2 of 08.12.2012; M7.2 of 03.20.2008.

In the case of M7.2 of 02.12.14, NOAA-18 OLR survey for January - February shows that the initial indication of building an atmospheric anomaly was detected in the period 20 - 30 of January (10 - 20 days before the mainshock) and maximum reached on January 21 eastward from the epicenter along Altyn Tagh fault. The OLR reference field was built for the entire period of 2004 - 2014.

In Figure 2 OLR time series also show anomalies that appear in the same area but other periods. On July 2013, September 2013 and March 2014, there are other significant OLR anomalies (i.e., A_index > 2). For example, the second-largest OLR anomaly in 2014 appeared after the pre-earthquake sign is starting at the beginning of March. An earthquake with Magnitude M5.4 has occurred on 2014-03-30 at 17:10:15.0 in Western Xizang (31.49N, 86.73E), according to the CEA catalog. Some additional analysis has shown that the largest picks $(\mathrm{A}>2)$ probably indicate other earthquake processes in the area.

FY-2D OLR data show a similar trend in detecting OLR signals by revealing anomalous value with the persistence of more than 9 hours on January 31, 2014. The 2012 (M 6.2) and 2008 (M7.2) event shows similar OLR anomalies (the 2012 events have the smallest value) that were built near to the epicenter area, over the major Altyn Tagh fault lines within 10-15 days before the seismic event and provides information about major fault activation in this area. A possible explanation of these results can provide the Lithosphere-Atmosphere -Ionosphere Coupling (LAIC) concept, which suggests physical links between the different atmospheric variations and tectonic activity [Pulinets and Ouzounov, 2011]. The primary process is the air ionization produced by the increased geogas emanation (CO2, $\mathrm{CH} 4$, radon) from the Earth's crust in the vicinity of active tectonic faults. The near-earth surface processes include air molecules ionization (by a-particles - a product of radon decay), which leads to the formation of complex molecular ions and the formation of large ion clusters up to aerosol size. This chain of events leads to changes in the air conductivity and the latent heat release (increasing of air temperature) due to water molecules attachment (condensation) to ions [Prasad et al., 2005; Pulinets et al., 2006]. Our findings provided evidence of the thermal buildup in increasing mean air temperature in the atmosphere. The initial increase in the ACP, T, and drops in RH have been followed (see Table 2) by the acceleration in the outgoing earth radiation with maxima on March 10, 2008 (M7.3 of 03.20.2008), July 24, 2012 (M6.2 of 08.12.2012) and January 21, 2014 (M7.2 of 02.12.2014), Figure 2a, b, c.

The increase of ACP, T, and drop of RH was followed by OLR anomalies clearly in M7.2 of March 20, 2008. For the two other cases, this sequence is not the same order. The cause for this bias probably is driven by two factors: $1 /$ The Hotan weather station from which computed T, RH, and ACP were computed is located closer to the epicenter of M7.2 of 2008 that to the other two epicenters, and the reading of the ground is more accurate for the 2008 event; and 2/ OLR is based on pixel averaging of $100 \mathrm{~km}$ in radius, which could be difficult to correlate with a single point of observation from the ground. 
Our results show the re-occurrence of transient anomalies in the atmosphere in advance of the three major earthquakes in Xinjiang province, China - M7.3 in 2008, M6.3 in 2012, and M7.2 in 2014. These also suggest that systematic use of multi-parameters and multisensory satellite and ground type of observation provides additional physical validation of pre-earthquake anomalies triggered by the coupling processes between the lithosphere and atmosphere.

Acknowledgments. The authors thank NOAA's Climate Prediction Center and China Meteorological Administration (CMA) for OLR data to China Earthquake Administration (CEA) for earthquake catalog data, and NOAA NCDC for providing global in-situ temperature data. The authors thank the International Space Science Institute (Bern, Beijing) for the international support of the team "Validation of Lithosphere-Atmosphere-Ionosphere-Magnetosphere Coupling (LAIMC) as a concept for geospheres interaction by utilizing space-borne multi-instrument observations". Thanks to the two anonymous reviewers for their thoughtful comments and recommendations.

\section{REFERENCES}

Boyarchuk K.A., A.V. Karelin , A.V. Nadolski (2010). Statistical analysis of the chemical potential correction value of the water vapor in atmosphere on the distance from earthquake epicenter, The issues of electro mechanics, 116, 39-46.

Cervone, G., S. Maekawa, R.P. Singh, M. Hayakawa, M. Kafatos and A. Shvets (2006). Surface latent heat flux and nighttime LF anomalies prior to the Mw=8.3Tokachi-Oki earthquake, Nat. Hazards Earth Syst. Sci., 6, 109114.

Deng Q.D., (2007), Active tectonics map of China, Seismological Press, Beijing.

Gruber A. and A. F. Krueger, (1984). The Status of the NOAA Outgoing Longwave Radiation Data Set. Bull. Amer. Meteor. Soc., 65, 9, 958-962.

Hattori, K., A. Serita, C. Yoshino, M. Hayakawa and N. Isezaki, (2006). Singular spectral analysis and principal component analysis for signal discrimination of ULF geomagnetic data associated with 2000 Izu Island Earthquake Swarm, Phy. Chem. Earth Parts A/B/C, 31, 4-9, 281-291.

Jing F., H. Wang, S. Hing, Y. Dong (2016). Thermal infrared variation associated with strong earthquakes in Xinjiang using satellite data, 2016 IEEE International Geoscience and Remote Sensing Symposium (IGARSS), https://doi.org/10.1109/IGARSS.2016.7729740

Liu, J. Y., Y.J. Chuo, S.J. Shan, Y.B. Tsai, Y.I. Chen, S.A. Pulinets. and S.B. Yu (2004), Pre-earthquake ionospheric anomalies registered by continuous GPS TEC measurement, Annales Geophysicae, 22, 1585-1593.

Liu, J. Y., Y. I. Chen, C. H. Chen, and K. Hattori (2010). Temporal and spatial precursors in the ionospheric GPS total electron content observed before the 26 December 2004 M9.3 Sumatra? Andaman Earthquake, J. Geophys. Res. A: Space Physics, 115, (9), A09312

Lisi M; C. Filizzola, N. Genzano, C.S. L. Grimaldi, T. Lacava, F. Marchese, G. Mazzeo, N. Pergola, V. Tramutoli (2010). A study on the Abruzzo 6 April 2009 earthquake by applying the RST approach to 15 years of AVHRR TIR observations, Nat. Hazards Earth Syst. Sci., 10, 395- 406.

Mehta, A. and J. Susskind (1999). Outgoing Longwave Radiation from the TOVS Pathfinder Path A Data Set, J. Geophys. Res., 104,12193-12212.

Nemec, F, O. Santolı'k, M. Parrot and J. J. Berthelier (2008). Spacecraft observations of electromagnetic perturbations connected with seismic activity, Geophys. Res. Lett., 35, L05109, doi:10.1029/2007GL032517.

Ohring, G. and A. Gruber (1982). Satellite radiation observations and climate theory, Advance in Geophysics., 25, 237-304.

Ouzounov D., N. Bryant, T. Logan, S. Pulinets, P. Taylor (2006). Satellite thermal IR phenomena associated with some of the major earthquakes in 1999-2004, Physics and Chemistry of the Earth, 31,154-163.

Ouzounov D., D. Liu, C. Kang, G. Cervone, M. Kafatos, P. Taylor (2007). Outgoing Long Wave Radiation Variability from IR Satellite Data Prior to Major Earthquakes, Tectonophysics, 431, 1-2, 211-220.

Ouzounov D., S. Pulinets, A. Romanov, A. Romanov Jr., K. Tsybulya, D. Davydenko, M. Kafatos and P. Taylor (2011). Atmosphere-Ionosphere Response to the M9 Tohoku Earthquake Reviled by Joined Satellite and Ground 


\section{Dimitar Ouzounov et al.}

Observations, Earthquake Science, 24, 557-564.

Ouzounov D, S. Pulinets, Ke Sun, Xuhui Shen, M. Kafatos (2015). Space-borne observations of pre-earthquake atmospheric signals associated with major seismicity in Xinjiang, China (2008-2014) Japan Geoscience Union, Chiba, Japan, May 24-28.

Ouzounov D, S. Pulinets, M. C. Kafatos, and P. Taylor, (2018). Thermal Radiation Anomalies Associated with Major Earthquakes., in Pre-Earthquake Processes: A Multidisciplinary Approach to Earthquake Prediction Studies, edited by D. Ouzounov, S. Pulinets, K .Hattori, and P.Taylor, Geophysical Monograph 234, American Geophysical Union, John Wiley \& Son, 259-277.

Ouzounov D, S. Pulinets, K. Hattori, P. Taylor (Eds) Pre-Earthquake Processes: A Multidisciplinary Approach to Earthquake Prediction Studies, AGU Geophysical Monograph 234, Wiley, 2018, 384.

Pergola N.; C. Aliano, I. Coviello, C. Filizzola, N. Genzano, T. Lacava, M. Lisi, G. Mazzeo, V. Tramutoli (2010). Using RST approach and EOS-MODIS radiances for monitoring seismically active regions: a study on the 6 April 2009 Abruzzo earthquake, Nat. Hazards Earth Syst. Sci. 10, 239-249.

Prasad, B.S.N., T.K. Nagaraja, M.S. Chandrashekara, L. Paramesh, M.S. Madhava (2005). Diurnal and seasonal variations of radioactivity and electrical conductivity near the surface for a continental location Mysore, India, Atmosph. Res.,76, 65-77

Pulinets S. and K. Boyarchuk (2004). Ionospheric Precursors of Earthquakes, Springer, Berlin, Germany, 315.

Pulinets S., D. Ouzounov, A. Karelin, K. Boyarchuk, L. Pokhmelnykh (2006). The Physical Nature of Thermal Anomalies Observed Before Strong Earthquakes, Phys. Chem. Earth, 31, 4-9, 143-153.

Pulinets S. and D. Ouzounov (2011). Lithosphere-Atmosphere-Ionosphere Coupling (LAIC) model - an unified concept for earthquake precursors validation, J. Asian Earth Sci., 41, 4-5, 371-382.

Pulinets S., D. Davidenko (2014). Ionospheric precursors of earthquakes and Global Electric Circuit, Adv. Space Res., 53, 709-723

Pulinets S. and D. Ouzounov, (2018) The Possibility of Earthquake Forecasting: Learning from nature, IOP Publishing, 168.

Sun, K., D. Ouzounov, S. A. Pulinets, X. Shen and M. Kafatos (2014). Atmospheric Responses to Pre-earthquake Processes Revealed by Satellite and In-situ Observations. Case Study for XinJiang, China (2008-2014), AGU Fall Meeting Abstracts, A3854 http://adsabs.harvard.edu/abs/2014AGUFMNH31A3854S.

Tramutoli, V., V. Cuomo, C. Filizzola, N. Pergola, C. Pietrapertosa (2005). Assessing the potential of thermal infrared satellite surveys for monitoring seismically active areas. The case of Kocaeli (İzmit) earthquake, August 17th, 1999, Remote Sens. Environ., 96, 3-4, 409-426.

Tramutoli, V., C. Aliano, R. Corrado, C. Filizzola, N. Genzano, M. Lisi, G. Martinelli, N. Pergola (2013). On the possible origin of Thermal Infrared Radiation (TIR) anomalies in earthquake-prone areas observed using Robust Satellite Techniques (RST). Chemical Geology, 339, 157-168.

Tronin, A., M. Hayakawa, and O. Molchanov (2002). Thermal IR satellite data application for earthquake research in Japan and China, J. Geodynamics, 33, 519-534.

Toutain, J.P. and J.C. Baubron (1998), Gas geochemistry and seismotectonics: a review. Tectonophysics, 304, 1-27.

Xiong, P., X. H. Shen, Y. X. Bi, C. L. Kang, L. Z. Chen, F. Jing, Y. Chen (2010). Study of outgoing long wave radiation anomalies associated with Haiti earthquake. Nat.Hazards Earth Syst. Sci. 10, 2169-2178.

Wu X. (2008) OLR inverse model for geostationary meteorological satellite FY-2D (in Chinese), Meteorol. Sci. Tech., 36: 634-638.

"CORRESPONDING AUTHOR: Dimitar OUZOUNOV, 